\title{
Anaerobic degradation of cyclohexane by sulfate-reducing bacteria from hydrocarbon-contaminated marine sediments
}

\author{
Ulrike Jaekel ${ }^{1}$, Johannes Zedelius ${ }^{1}$, Heinz Wilkes ${ }^{2}$ and Florin Musat ${ }^{1,3 *}$ \\ Department of Microbiology, Max Planck Institute for Marine Microbiology, Bremen, Germany \\ ${ }^{2}$ Organic Geochemistry, Helmholtz Centre Potsdam GFZ German Research Centre for Geosciences, Potsdam, Germany \\ ${ }^{3}$ Isotope Biogeochemistry, Helmholtz Centre for Environmental Research - UFZ, Leipzig, Germany
}

\section{Edited by:}

Inês A. Cardoso Pereira,

Universidade Nova de Lisboa,

Portugal

Reviewed by:

Amy V. Callaghan, University of Oklahoma, USA

Bernhard Schink, University of

Konstanz, Germany

\section{*Correspondence:}

Florin Musat, Department of Isotope Biogeochemistry, Helmholtz Centre for Environmental Research - UFZ, Permoserstr. 15, 04318 Leipzig,

Germany

e-mail: florin.musat@ufz.de
The fate of cyclohexane, often used as a model compound for the biodegradation of cyclic alkanes due to its abundance in crude oils, in anoxic marine sediments has been poorly investigated. In the present study, we obtained an enrichment culture of cyclohexane-degrading sulfate-reducing bacteria from hydrocarbon-contaminated intertidal marine sediments. Microscopic analyses showed an apparent dominance by oval cells of $1.5 \times 0.8 \mu \mathrm{m}$. Analysis of a $16 \mathrm{~S}$ rRNA gene library, followed by whole-cell hybridization with group- and sequence-specific oligonucleotide probes showed that these cells belonged to a single phylotype, and were accounting for more than $80 \%$ of the total cell number. The dominant phylotype, affiliated with the Desulfosarcina-Desulfococcus cluster of the Deltaproteobacteria, is proposed to be responsible for the degradation of cyclohexane. Quantitative growth experiments showed that cyclohexane degradation was coupled with the stoichiometric reduction of sulfate to sulfide. Substrate response tests corroborated with hybridization with a sequence-specific oligonucleotide probe suggested that the dominant phylotype apparently was able to degrade other cyclic and $n$-alkanes, including the gaseous alkane n-butane. Based on GC-MS analyses of culture extracts cyclohexylsuccinate was identified as a metabolite, indicating an activation of cyclohexane by addition to fumarate. Other metabolites detected were 3-cyclohexylpropionate and cyclohexanecarboxylate providing evidence that the overall degradation pathway of cyclohexane under anoxic conditions is analogous to that of $n$-alkanes.

Keywords: cyclohexane, anaerobic, marine sediments, sulfate-reducing bacteria, Desulfosarcina

\section{INTRODUCTION}

Cycloalkanes are major constituents of crude oils, accounting for $20-40 \%$ of the total hydrocarbon fractions (Tissot and Welte, 1984), and are common in refined petroleum products. Cyclopentane, cyclohexane and their alkylated derivatives, especially methylcyclopentane and methylcyclohexane are most abundant (Tissot and Welte, 1984). Due to their wide industrial use as solvents and raw materials in the chemical industry, cycloalkanes are common environmental contaminants. Biodegradation studies of oil spills in ocean surface waters have shown that cycloalkanes were degraded to a lesser extent than $n$-alkanes (Brown and Huffman, 1976; Leahy and Colwell, 1990). This recalcitrance toward biodegradation can be in part attributed to the higher toxicity of cyclic alkanes as compared to $n$-alkanes (Sikkema et al., 1994, 1995). Many studies of cycloalkane biodegradation used cyclohexane as a model compound (Stirling et al., 1977; Anderson et al., 1980; Trower et al., 1985; Rouviere and Chen, 2003). Cyclohexane has the most stable chemical structure of all cycloalkanes, due to the lowest energy strain of the C-Cbonds (Bruice, 2004). Cyclohexane has a low solubility in water $\left(0.68 \mathrm{mM}\right.$ at $\left.25^{\circ} \mathrm{C}\right)$, and is a relatively volatile hydrocarbon (boiling point $80.7^{\circ} \mathrm{C}$ ) (Dean, 1992). A relatively low number of aerobic bacterial strains able to degrade cyclohexane have been isolated. These were affiliated with the Actinobacteria (Stirling et al., 1977), or with the Proteobacteria (Anderson et al., 1980; Trower et al., 1985; Rouviere and Chen, 2003). Under aerobic conditions, cylohexane is activated by a cyclohexane monooxygenase forming cyclohexanol, which is further oxidized to cyclohexanone, caprolactone and adipate (Perry, 1984; Cheng et al., 2002). Recent studies indicated that aerobic cyclohexane-degrading bacteria may be among the first microorganisms to be enriched in situ as a response to oil spills. During the early stages of the Deepwater Horizon oil spill, hydrocarbons released into deepsea waters led to the in situ enrichment of an uncultivated group of Oceanospirillales (Hazen et al., 2010; Redmond and Valentine, 2012). Subsequent single-cell genome sequencing showed that the enriched Oceanospirillales contained a near-complete pathway for cyclohexane oxidation (Mason et al., 2012). In addition, genes coding for the cyclohexane degradation pathway were found in metagenome and metatranscriptome libraries, indicating that cyclohexane-degrading bacteria were abundant and active in the crude oil contaminated waters (Mason et al., 2012).

Anaerobic degradation of cycloalkanes was shown with a sulfate-reducing enrichment culture obtained with ethylcyclopentane from a gas condensate-contaminated aquifer (Rios-Hernandez et al., 2003), and with a nitrate-reducing 
enrichment culture growing with cyclohexane, obtained from freshwater sediments (Musat et al., 2010). In addition, anaerobic degradation of cycloalkanes was demonstrated using sediment samples from a hydrocarbon-contaminated aquifer provided with gasoline and gas condensates (Townsend et al., 2004). Under anaerobic conditions, cycloalkanes are activated by addition to fumarate yielding cycloalkylsuccinate derivatives, a mechanism similar to that of $n$-alkane activation catalyzed by glycyl radical enzymes (Rabus et al., 2001; Callaghan et al., 2008; Grundmann et al., 2008; Jarling et al., 2012). This was demonstrated by metabolite analyses of a sulfate-reducing enrichment culture growing with ethylcyclopentane (Rios-Hernandez et al., 2003), and of a nitrate-reducing enrichment culture with cyclohexane (Musat et al., 2010). In addition, co-activation of cyclopentane to cyclopentylsuccinate was observed in cultures of a denitrifying strain growing with $n$-alkanes from crude oil, while cyclopentane alone did not serve as a growth substrate (Wilkes et al., 2003).

Anaerobic pure cultures able to grow with cycloalkanes have not been reported so far. Phylotypes related to Desulfotomaculum sp., identified by DGGE analyses, have been proposed to be involved in ethylcyclopentane degradation in a sulfate-reducing enrichment culture (Rios-Hernandez et al., 2003). Based on hybridization with oligonucleotide probes, a Geobacter sp.-related phylotype was proposed to be responsible for cyclohexane degradation in a nitrate-reducing enrichment culture (Musat et al., 2010). Nevertheless, the identity of anaerobic cycloalkanedegrading microorganisms is largely unknown. Such microorganisms have not been identified so far in marine environments, despite the fact that the oceans receive massive inputs of crude oil (for example the recent Deepwater Horizon spill, e.g., Atlas and Hazen, 2011). In the present study, we enriched cyclohexane-degrading, sulfate-reducing bacteria from marine sediments contaminated with hydrocarbons. The microorganisms in the enrichment culture were identified by hybridization with sequence-specific oligonucleotide probes. We analyzed the ability of the enriched bacteria to degrade other cyclic and $n$ alkanes, by short-term incubations with dense-cell suspensions. Also, we investigated the pathway of cyclohexane activation and further degradation, by analysis of metabolites. Based on the metabolites detected, we propose a pathway for cyclohexane degradation under sulfate-reducing conditions.

\section{MATERIALS AND METHODS CHEMICALS}

Cyclopentane, cyclohexane, methylcyclopentane, methylcyclohexane, $n$-pentane, $n$-hexane, benzene and toluene of analytical grade were purchased from Merck (Damstadt, Germany). 2,2,4,4,6,8,8-Heptamethylnonane (HMN), cyclohexylsuccinic acid, 3-cyclohexylpropionic acid and cyclohexanecarboxylic acid were purchased from Sigma-Aldrich (Steinheim-Germany). The gaseous alkanes ethane, propane and $n$-butane of purity 3.5 were purchased from Air Liquide (Düsseldorf, Germany).

\section{SOURCE OF ORGANISMS, CULTURE MEDIA AND CULTIVATION TECHNIQUES}

Anoxic sediment from a hydrocarbon-contaminated lagoon in the Mediterranean was used to establish enrichment cultures.
Collected sediment was homogenized by mixing with a metal spoon in an anoxic tent, under a $\mathrm{N}_{2}: \mathrm{CO}_{2}(9: 1, \mathrm{v} / \mathrm{v})$ atmosphere. Enrichment cultures were established in $100 \mathrm{ml}$ flat glass bottles containing $50 \mathrm{ml}$ of defined $\mathrm{NaHCO}_{3} / \mathrm{CO}_{2}$-buffered artificial sea water medium (Widdel and Bak, 1992), $5 \mathrm{ml}$ homogenized sediment as inoculum, and a headspace of $\mathrm{N}_{2}: \mathrm{CO}_{2}(9: 1, \mathrm{v} / \mathrm{v})$. The bottles were sealed with butyl-rubber stoppers, and provided with $2.5 \mathrm{ml}$ of $\mathrm{HMN}$ as an inert carrier phase, containing $0.5 \%$ $(\mathrm{v} / \mathrm{v})$ cyclohexane. Control bottles without addition of cyclohexane were set up in a similar way. Bottles were incubated at $28^{\circ} \mathrm{C}$ in a nearly horizontal position, in order to avoid direct contact of the carrier phase with the stoppers, and to maximize the surface of the carrier-medium interface (Rabus and Widdel, 1995). Subsequent cultures were inoculated with $10 \%(\mathrm{v} / \mathrm{v})$ of an active culture. Cultures containing sediment were incubated without shaking, while later sediment-free cultures were incubated with slow $(60 \mathrm{rpm})$ horizontal shaking. Sediment-free cultures were amended with $3 \mathrm{ml} \mathrm{l}^{-1}$ trace element solution (Widdel and Bak, 1992). Quantitative growth experiments were set up in 120-ml round flat bottles containing $90 \mathrm{ml}$ medium, $10 \mathrm{ml}$ inoculum and $5 \mathrm{ml} \mathrm{HMN}$ with 0.5 or $0.2 \%$ (v/v) cyclohexane. Sterile bottles with cyclohexane and inoculated bottles without addition of cyclohexane were used as controls. For extraction of metabolites, cultures were prepared in a similar manner as the quantitative growth experiments, with the use of culture medium with a limited amount of sulfate $(5 \mathrm{mM})$.

Substrate tests with other hydrocarbons were performed with $15 \times$ concentrated cell suspensions. For preparation of concentrated cell suspensions, a total volume of $2100 \mathrm{ml}$ of cyclohexanegrown cultures was separated inside an anoxic tent $\left(\mathrm{N}_{2}: \mathrm{CO}_{2}\right.$ 9:1 v/v) from the carrier phase using a separatory funnel, centrifuged, and suspended in $140 \mathrm{ml}$ of anoxic medium. Aliquots of $10 \mathrm{ml}$ were distributed in $15 \mathrm{ml}$ butyl stoppered cultivation tubes and provided with the following substrates (concentration given as percent $\mathrm{v} / \mathrm{v}$ in $\mathrm{HMN}$, unless otherwise stated): cyclopentane $(0.2 \%)$, methylcyclopentane $(0.5 \%)$, methylcyclohexane $(0.5 \%)$, ethane ( $5 \mathrm{ml}$ gas in the headspace), propane $(5 \mathrm{ml}$ gas in the headspace), $n$-butane ( $5 \mathrm{ml}$ gas in the headspace), $n$-pentane $(1 \%), n$-hexane $(1 \%)$, benzene $(0.5 \%)$, and toluene $(0.5 \%)$. For the substrates that were added dissolved in HMN, a volume of $0.5 \mathrm{ml} \mathrm{HMN}$ containing the indicated substrate concentration was added per tube. Unamended controls were prepared in a similar manner. In order to provide the cells with a starting substrate, assuming that enzymes other than those involved in cyclohexane degradation might be required for the degradation of the tested substrates, all cultures, including the negative controls were amended with $50 \mu \mathrm{l}$ of $\mathrm{HMN}$ with $0.5 \%(\mathrm{v} / \mathrm{v})$ cyclohexane ( $10 \%$ of the regular amount of cyclohexane), as a starter substrate. Substrate tests results were confirmed with two independent incubations.

\section{ANALYTICAL METHODS}

Sulfide concentrations were determined by photometric measurements $(\lambda=480 \mathrm{~nm})$ of colloidal $\mathrm{CuS}$, as described elsewhere (Cord-Ruwisch, 1985). Cyclohexane concentrations in HMN were measured by headspace analysis. The measurement is based on gas phase equilibrium with the carrier phase at constant 
temperatures $\left(28^{\circ} \mathrm{C}\right)$. Volumes of $0.1 \mathrm{ml}$ headspace were withdrawn with gas-tight, $\mathrm{N}_{2}$-flushed syringes, and injected without a split into a Shimadzu GC-14B gas chromatograph, equipped with a Supel-Q PLOT column $(30 \mathrm{~m} \times 0.53 \mathrm{~mm}, 30 \mu \mathrm{m}$ film thickness; Supelco, Bellefonte, USA) and a flame ionization detector. The oven temperature was maintained at $140^{\circ} \mathrm{C}$, and the injection and detection temperatures were maintained at 150 and $280^{\circ} \mathrm{C}$, respectively. The carrier phase was $\mathrm{N}_{2}$ at a flow rate of $3 \mathrm{ml} \mathrm{min} \mathrm{m}^{-1}$. Samples were analyzed in triplicates. An external calibration was built by gas phase measurements of bottles with defined concentrations of cyclohexane in $\mathrm{HMN}$, equilibrated at $28^{\circ} \mathrm{C}$.

Prior to extraction of metabolites, cultures were inactivated by heating on a water bath at $85^{\circ} \mathrm{C}$ for $30 \mathrm{~min}$, cooled down to room temperature and acidified using $\mathrm{HCl}$ to a $\mathrm{pH}$ of about 2 . The culture medium was separated from the HMN phase with separatory funnels, and extracted three times with 1.5 volumes of dichloromethane (Rabus et al., 2001; Wilkes et al., 2002). The extracts were combined and dried over anhydrous $\mathrm{Na}_{2} \mathrm{SO}_{4}$. Sterile cultures with cyclohexane and inoculated cultures without cyclohexane were used as controls. Extracts were methylated using a solution of diazomethane in diethyl ether and subsequently analyzed using a Trace GC-MS system (Thermo Scientific, Bremen, Germany). The gas chromatograph was equipped with a 5\% phenyl polysilphenylene-siloxane capillary column (BPX-5, SGE; $50 \mathrm{~m} \times 0.22 \mathrm{~mm}, 0.25 \mu \mathrm{m}$ film thickness). The column temperature was initially held at $50^{\circ} \mathrm{C}$ for $1 \mathrm{~min}$, then heated to $310^{\circ} \mathrm{C}$ at a rate of $3^{\circ} \mathrm{C} \mathrm{min}^{-1}$ with a final hold time of $30 \mathrm{~min}$. Helium was used as the carrier gas. The PTV injector temperature was programmed from 50 to $300^{\circ} \mathrm{C}(10 \mathrm{~min}$ isothermal) at a rate of $10^{\circ} \mathrm{C} \mathrm{s}^{-1}$, and the injection volume was $1 \mu \mathrm{l}$ in splitless mode. Mass spectra were recorded from $\mathrm{m} / z 50$ to 600 . Identification of metabolites (as methyl esters) was based on comparison of retention times and mass spectra with those of authentic standards.

\section{CONSTRUCTION OF $16 S$ rRNA GENE LIBRARIES AND PHYLOGENETIC ANALYSIS}

Genomic DNA was extracted from the enrichment culture and used in PCR reactions to amplify nearly full-length 16SrRNA genes with bacteria-specific primers (Musat et al., 2006). The PCR products were purified using the QIAquick Gel Extraction kit (Qiagen, Hilden, Germany), cloned into the pCR4 vector (TOPOTA cloning kit, Invitrogen, Groningen, Netherlands) and transformed into E. coli Top 10 competent cells (Invitrogen). Positive clones were sequenced using the ABI Prism BigDye Terminator $\mathrm{v}$ 3.0 cycle sequencing kit and an ABI Prism 3100 Genetic Analyzer (Applied Biosystems, Darmstadt, Germany). Gene libraries were screened for phylotypes affiliated with the Deltaproteobacteria by partial sequencing with the primer 517f (Muyzer et al., 1993). Clones affiliated with the Deltaproteobacteria were fully sequenced using the primers M13F and M13R (Invitrogen). Sequences were assembled with the DNA Baser software (www. dnabaser.com) and analyzed using the BLAST(N) algorithm (Altschul et al., 1990). For phylogenetic reconstruction, nearly full-length sequences (>1300 bp) were aligned to those of the Silva database (Pruesse et al., 2007). Phylogenetic trees were constructed in ARB (Ludwig et al., 2004) using neighbor joining, maximum likelihood and maximum parsimony, and by applying different sets of filters. The sequence data have been deposited in the DDBJ, EMBL and GenBank databases under accession numbers KP009598-KP009615.

\section{MICROSCOPY AND WHOLE CELL HYBRIDIZATION}

For phase-contrast images $10 \mu \mathrm{l}$ aliquots from living cultures were transferred onto agar-coated $(1 \% \mathrm{w} / \mathrm{v})$ glass slides and covered with a cover slip. Cells were examined with a Zeiss Axioskop 50 microscope (Zeiss; Oberkochen, Germany). For whole cell hybridization, cells were fixed with $2 \%$ paraformaldehyde in $1 \times$ phosphate-buffered saline (PBS; $10 \mathrm{mM}$ sodium phosphate $\mathrm{pH}$ $7.2,130 \mathrm{mM} \mathrm{NaCl}$ ) for $1 \mathrm{~h}$ at room temperature, washed with $1 \times$ PBS, and stored in $1 \times$ PBS-ethanol $(1: 1)$ at $-20^{\circ} \mathrm{C}$. Aliquots of fixed cells were filtered onto $0.2 \mu \mathrm{m}$ pore GTTP polycarbonate filters (Millipore, Eschborn-Germany). Cells on filters were hybridized with Horseradish peroxidase (HRP)-labeled 16S rRNA-targeted oligonucleotide probes. Signal amplification was done as described elsewhere (Pernthaler et al., 2002) using Alexa $488^{\circledR}$ tyramides (Invitrogen). Thereafter, all cells were additionally stained with DAPI and microscopically counted as previously described (Snaidr et al., 1997). The hybridized, DAPI-stained cells were analyzed with a Zeiss Axioskop 2 mot plus fluorescence microscope (Zeiss), using a HC F36-525 filter (AHF, Tübingen, Germany) for probe signal recording and a F81360 filter (AHF, Tübingen, Germany) for DAPI signal recording. Images were acquired and processed using the Zeiss Axio Vision 4.0 software release 4.6.3 (Carl Zeiss Imaging Solutions; Hallbergmoos, Germany). The oligonucleotide probes used in this study, Cyhx28-EdB_152 (AGCAAGCCTTTCAGCATG; sequence-specific, this study), DSS658 (Manz et al., 1998), EUB338 (Amann et al., 1990) and NON338 (Amann et al., 1990) were purchased from Biomers GmbH (Ulm, Germany). The sequence-specific probe designed in this study (in ARB,

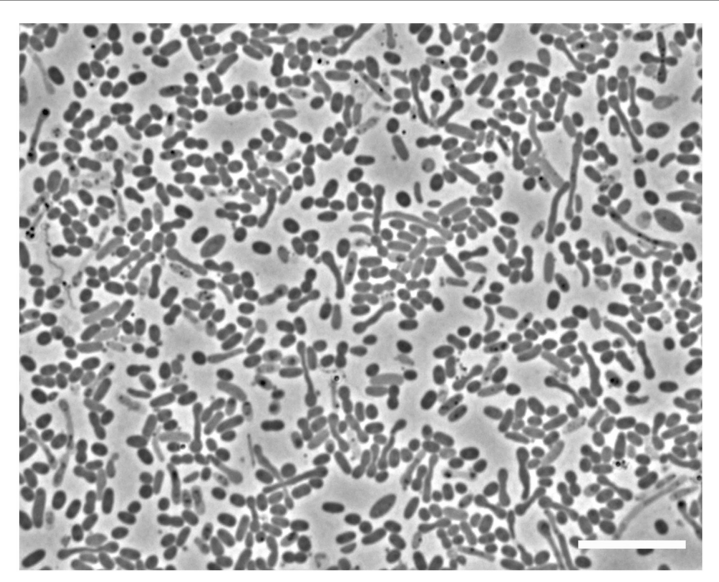

FIGURE 1 | Phase contrast microscopic image of cells in the enrichment culture Cyhx28-EdB. The enrichment appeared dominated by oval cells $(1.5 \times 0.8 \mu \mathrm{m}$, on average). Upon depletion of cyclohexane and accumulation of high concentrations of sulfide, elongated cells could be observed. Scale bar $=10 \mu \mathrm{m}$ 
after Hugenholtz et al., 2001), was evaluated for specificity in hybridization assays with increasing formamide [FA] concentrations (0-60\%, with $10 \%$ increment) with the enrichment culture as a positive target. The highest FA concentration where strong fluorescent probe signals were still observed was 20\% FA. Cultured strains with one or two mismatches were not available to serve as negative controls.

\section{RESULTS AND DISCUSSIONS ENRICHMENT AND PHYLOGENETIC ANALYSES OF CYCLOHEXANE-DEGRADING SULFATE-REDUCING BACTERIA}

Enrichment of cyclohexane-degrading bacteria with sulfate as the terminal electron acceptor was started with intertidal, hydrocarbon-contaminated marine sediments. Sulfide concentrations were monitored as a measure of cyclohexane-dependent sulfate reduction. After approximately 5 months of incubation, the incubation with added cyclohexane formed ca. $15 \mathrm{mM}$ sulfide vs. $8 \mathrm{mM}$ in the control incubation without cyclohexane. A sediment-free enrichment culture (Cyhx28-EdB), obtained by repeated transfers in fresh culture medium, formed $15 \mathrm{mM}$ sulfate within an incubation time of approximately 8 weeks (data not shown).

Microscopic analyses showed an apparent dominance by oval to rod-shaped cells of $1.5 \mu \mathrm{m}$ length $\times 0.8 \mu \mathrm{m}$ diameter, on average (Figure 1). Upon depletion of cyclohexane and formation of high concentrations of sulfide some cells showed an elongated morphology (Figure 1). Since attempts to isolate the cyclohexane-degrading microorganism in pure culture were not successful, the enrichment culture was further analyzed by molecular biology methods. Construction and analysis of a $16 \mathrm{~S}$ rRNA gene library $(n=96)$ showed that most of the sequences $(n=53)$ were affiliated with the Deltaproteobacteria. Of the Deltaproteobacterial sequences, the majority $(n=$ 42) were affiliated with the Desulfosarcina-Desulfococcus clade (>94\% sequence identity). Other Deltaproteobacteria-affiliated sequences were closely related to Desulfobacterium anilini $(n=4)$ and Desulfotignum balticum $(n=6)$ (Figure SI1). A large number of clones $(n=37)$ were closely related to sequences belonging to the OP3 cluster, a group within the Planctomycetes/Verrucomicrobia/Chlamydiae superphylum, from which no isolated strains have been reported so far (e.g., Rotaru et al., 2012). In an attempt to identify the putative most abundant microorganisms, the 16S rRNA gene was amplified using increasingly diluted DNA template. The PCR products from the highest template dilution yielding a result $\left(10^{-2}\right)$ were sequenced without cloning. The sequences obtained were identical with one of the clones affiliated with the Desulfosarcina-Desulfococcus cluster, Cyhx28-EdB-clone63 (Figure 2). Cyhx28-EdB-clone63 was closely related to sequences from the Amsterdam mud volcano (94.7\% identity; (Pachiadaki et al., 2011), Gulf of Cadiz mud volcano (>93\% identity), clone sequences from a naphthalene-degrading enrichment culture (Selesi et al., 2010), Guerrero Negro hypersaline mat clones (Harris et al., 2013) and Zodletone spring sediment clones (Youssef et al., 2012). The closest cultivated relatives were strain BuS5 (92.7\% identity; Kniemeyer et al., 2007), and dominant phylotypes in propane-

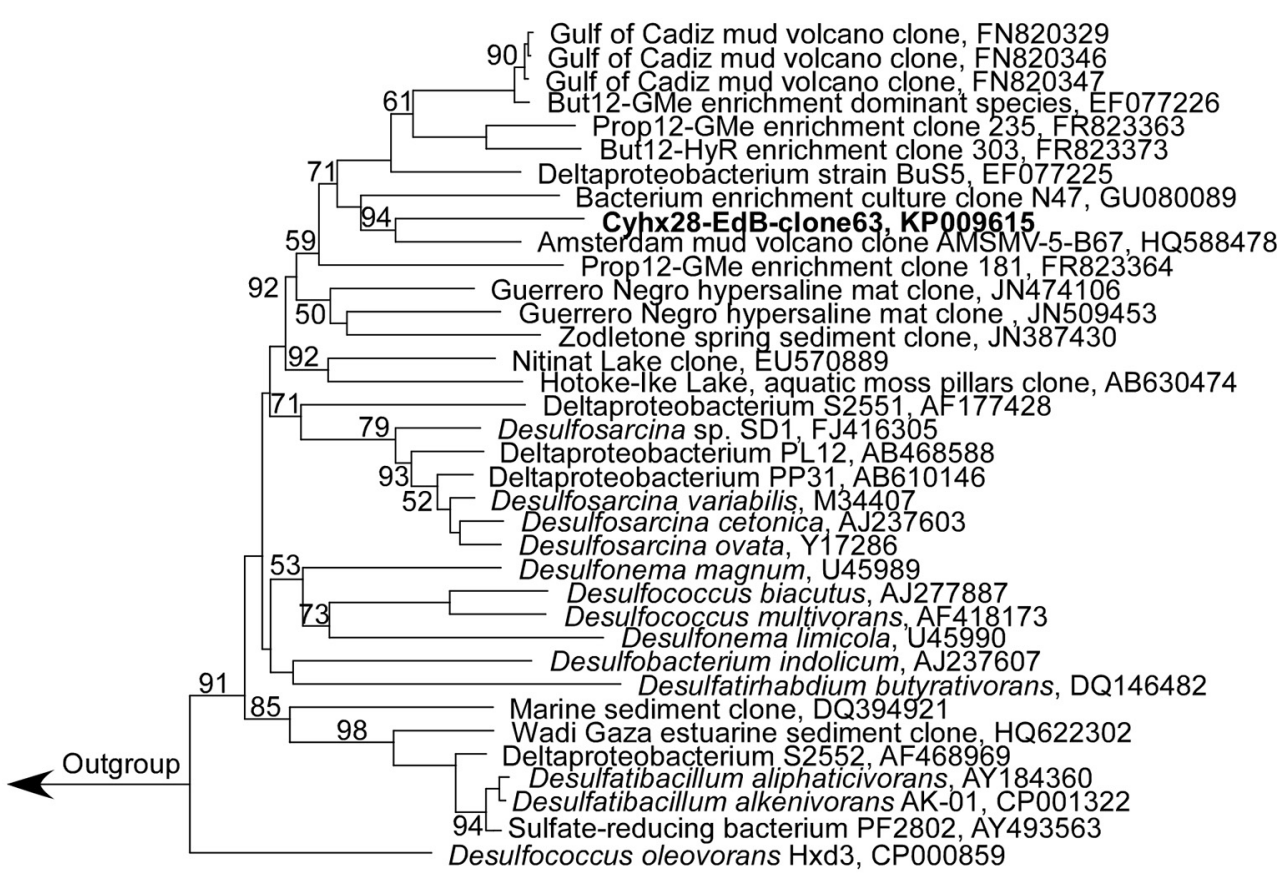

$10 \%$

FIGURE 2 | Phylogenetic affiliation of the most abundant phylotype in the enrichment culture, Cyhx28-EdB-clone63 (marked in bold-face). The phylogenetic tree was calculated in ARB by neighbor-joining, using only nearly full-length sequences (>1300 nt), with application of different sets of filters. The numbers next to nodes indicate bootstrap values higher than $50 \%$. The scale bar represents $10 \%$ estimated sequence divergence. 
and $n$-butane-degrading enrichment cultures from the Gulf of Mexico and Hydrate Ridge sediments (Kniemeyer et al., 2007; Jaekel et al., 2013). Substrate tests with strain BuS5 showed that this microorganism degraded only the gaseous alkanes propane and $n$-butane (Kniemeyer et al., 2007). Shorter (ethane and methane) or longer ( $n$-pentane and higher) alkanes did not serve as growth subtstrates. A similarly restricted substrate range was found for the enrichment cultures Prop12-GMe, But12-GMe, and But12-HyR, which also degraded only propane and $n$-butane (Jaekel et al., 2013).

The abundance of the phylotype represented by Cyhx28-EdBclone63 in the enrichment culture was further quantified by whole-cell hybridization. Hybridizations with the group-specific oligonucleotide probe DSS658, targeting most of the bacteria afiliated with the Desulfosarcina-Desulfococcus cluster, including Cyhx28-EdB-clone63, showed that this phylogenetic group accounted for $84.3 \%$ of the total cell number determined by DAPI staining (Figure 3). Further hybridizations with the sequencespecific oligonucleotide probe Cyhx28-EdB_152 showed that the phylotype Cyhx28-EdB-clone63 accounted for $80.2 \%$ of the total cell number (Figure 3). High abundance of single phylotypes has been found in other anaerobic, hydrocarbon-degrading enrichment cultures, for example with benzene under sulfatereducing conditions (Musat and Widdel, 2008), or with alkylbenzenes and $n$-alkanes under denitrifying conditions (Rabus et al., 1999). In addition, highly abundant phylotypes in enrichment cultures of sulfate-reducing bacteria degrading gaseous alkanes have been shown to be directly involved in hydrocarbon degradation by incubations with ${ }^{13} \mathrm{C}$-labeled substrates followed by nanoSIMS analyses (Jaekel et al., 2013). Considering the high abundance of the phylotype Cyhx28-EdB-clone63, we propose that it plays a very important role in the biodegradation of cyclohexane.

\section{STOICHIOMETRY OF CYCLOHEXANE DEGRADATION}

Quantitative growth experiments showed depletion of cyclohexane coupled to the reduction of sulfate to sulfide within about 100 days (Figure 4). No cyclohexane was consumed in sterile controls, and minor amounts of sulfide were produced in inoculated
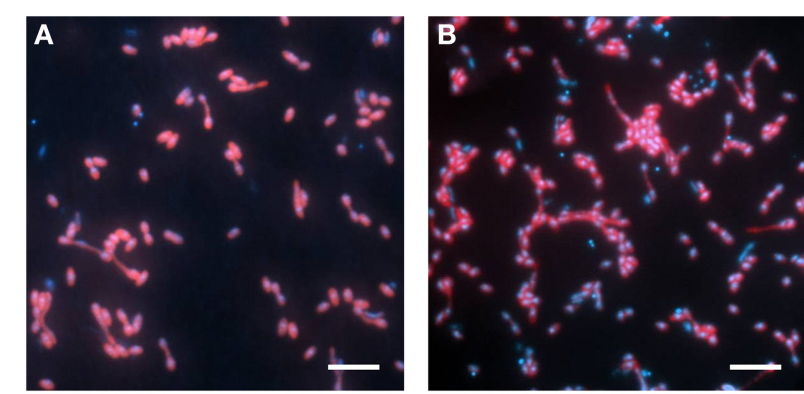

FIGURE 3 | Whole-cell hybridization (CARD-FISH) with the group-specific probe DSS658 (A) and with the sequence-specific probe Cyhx28-EdB_152 (B), showing the dominance of the phylotype

Cyhx28-EdB-clone63. The images show an overlay of probe (red) and DAPI (blue) signals. Scale bars $=5 \mu \mathrm{m}$. control cultures without addition of cyclohexane, probably due to carry over of small amounts of substrate during inoculation (Figure 4, Table 1). Calculation of the net electron balance from incubations with different cyclohexane concentrations $(2.4$ and $1.0 \mathrm{mmol}^{-1}$ ) yielded ratios close to the theoretical one for complete oxidation of cyclohexane to $\mathrm{CO}_{2}$ according to eq. 1 (Table 1).

$$
\begin{gathered}
2 \mathrm{C}_{6} \mathrm{H}_{12}+9 \mathrm{SO}_{4}^{2-} \rightarrow 12 \mathrm{HCO}_{3}^{-}+9 \mathrm{HS}^{-}+3 \mathrm{H}^{+} \\
\Delta G^{\mathrm{o}^{\prime}}=-202.6 \mathrm{~kJ}(\mathrm{~mol} \text { cyclohexane })^{-1}
\end{gathered}
$$

The observed stoichiometry could be due to complete oxidation of cyclohexane by the proposed microorganism, Cyhx28-EdBclone63, or to incomplete cyclohexane oxidation followed by the scavenging of the intermediates by other sulfate-reducing bacteria in the enrichment culture. The sulfate-reducing bacteria isolated so far with aliphatic or aromatic hydrocarbons as substrates are complete oxidizers, degrading the hydrocarbon substrate completely to $\mathrm{CO}_{2}$ (for an overview see Widdel et al., 2010). Among these are strains affiliated to the same phylogenetic group as the phylotype Cyhx28-EdB-clone63 (Desulfosarcina-Desulfococcus), degrading gaseous alkanes (strain BuS5 and dominant phylotypes in propane- and n-butane-degrading enrichment cultures; (Kniemeyer et al., 2007; Jaekel et al., 2013), n-alkanes $>\mathrm{C}_{6}$ (e.g., Aeckersberg et al., 1991; So and Young, 1999), or aromatic

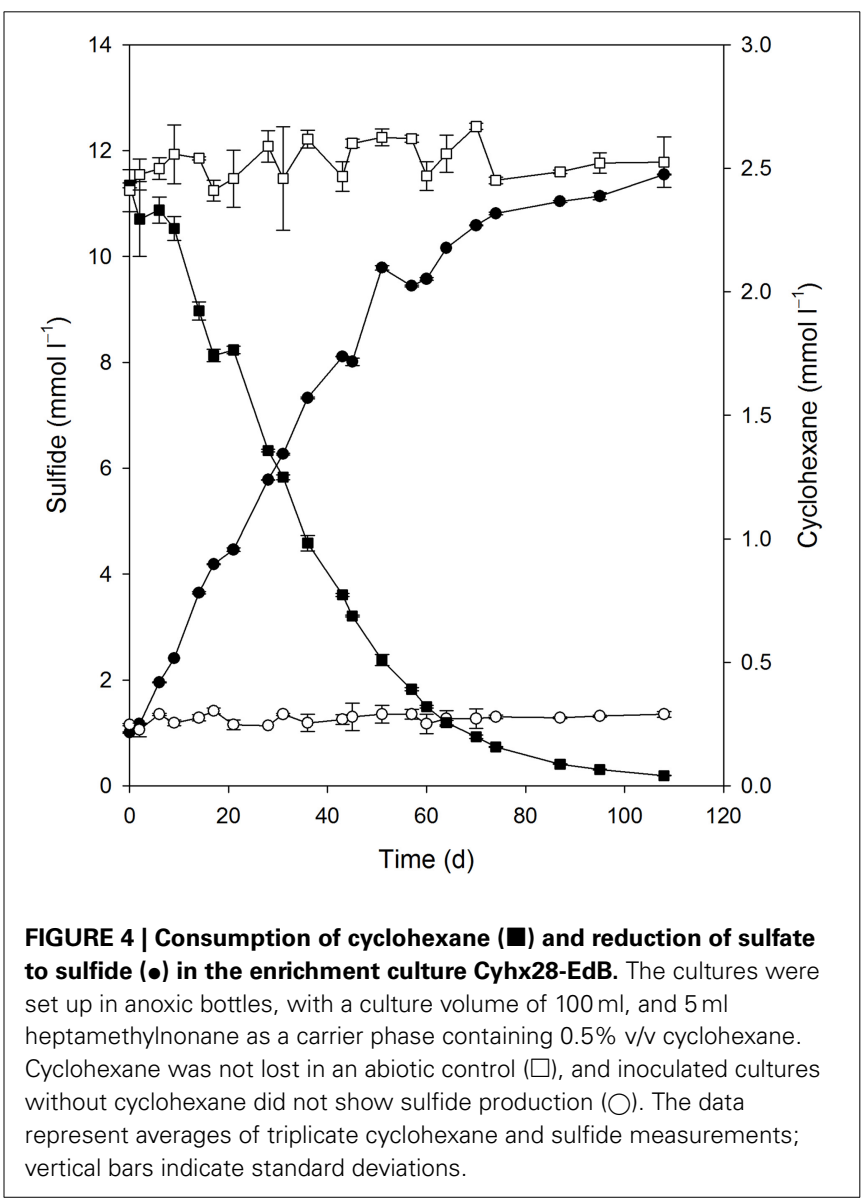


hydrocarbons (e.g., Harms et al., 1999). Complete oxidation of cycloalkanes under sulfate-reducing conditions has been reported so far with an enrichment culture growing with ethylcyclopentane (Rios-Hernandez et al., 2003). Based on these studies, the present calculations of the net electron balances for different cyclohexane concentrations, and the high abundance of the phylotype Cyhx28-EdB-clone63, we propose that the dominant phylotype has the ability to degrade cyclohexane completely to $\mathrm{CO}_{2}$; the other microorganisms in the enrichment culture may grow at the expense of excreted metabolites or dead biomass of the dominant phylotype. For example, recent metagenomic analyses of the $\mathrm{OP} 3$, which are the second most abundant phylogenetic group in the present enrichment culture based on clone frequency, identified genes typical of the tricarboxylic acid cycle (Glockner et al., 2010). One may speculate that the OP3 scavenge low-molecular mass fatty acids from the downstream cyclohexane degradation pathway.

\section{SUBSTRATE TESTS WITH HYDROCARBONS OTHER THAN CYCLOHEXANE}

We tested the ability of the enrichment culture Cyhx28-EdB to degrade other hydrocarbons than cyclohexane. To prevent false positive results by the enrichment of microorganisms other than the dominant phylotype upon addition of new substrates, the experiments were done with concentrated cell suspensions and incubated for a relatively short time. The enrichment culture responded without a lag phase to additions of other cyclic alkanes, e.g., cyclopentane, methylcyclopentane and methylcyclohexane (Figure 5A). Of the $n$-alkanes tested, the enrichment culture was apparently able to grow with $n$-pentane

Table 1 | Electron balance of the observed degradation of cyclohexane coupled to the reduction of sulfate to sulfide.

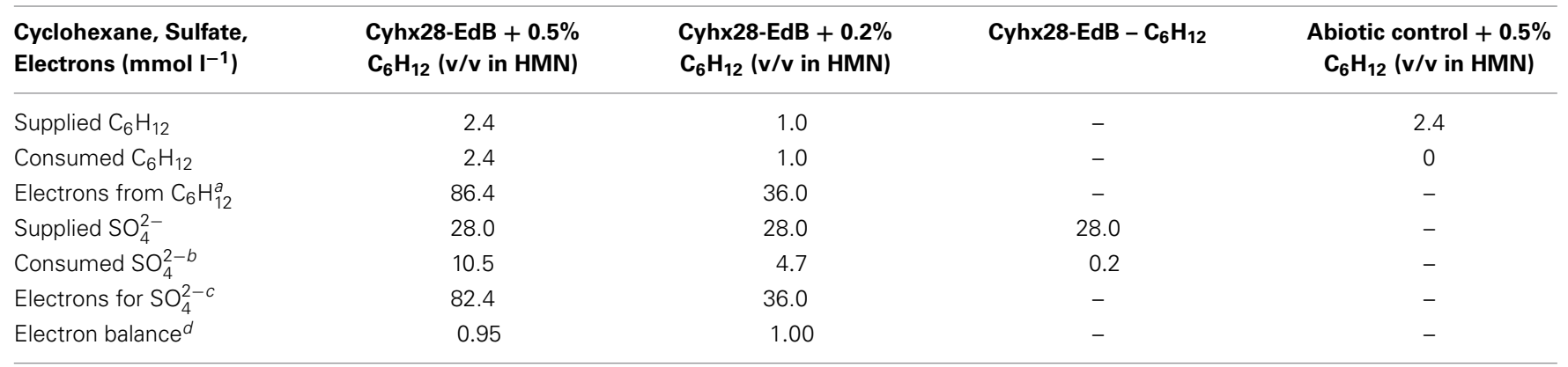

Parallel experiments were carried out, with different starting amounts of cyclohexane.

${ }^{a}$ Electrons from consumed $\mathrm{C}_{6} \mathrm{H}_{12}$ were calculated considering the complete oxidation: $\mathrm{C}_{6} \mathrm{H}_{12}+12 \mathrm{H}_{2} \mathrm{O} \rightarrow 6 \mathrm{CO}_{2}+36 \mathrm{H}^{+}+36 \mathrm{e}^{-}$.

${ }^{b}$ The amount of consumed $\mathrm{SO}_{4}^{2-}$ was determined by quantification of produced $\mathrm{H}_{2} \mathrm{~S}$ (corrected for the $\mathrm{H}_{2} \mathrm{~S}$ added as a reducing agent in the culture medium, $1 \mathrm{mmol}^{\mathrm{H}} \mathrm{\mu}$.

${ }^{c}$ Electrons for $\mathrm{SO}_{4}^{2-}$ reduction were calculated considering: $\mathrm{SO}_{4}^{2-}+8 \mathrm{e}^{-}+9 \mathrm{H}^{+} \rightarrow \mathrm{HS}^{-}+4 \mathrm{H}_{2} \mathrm{O}$. For calculation, the $\mathrm{H}_{2} \mathrm{~S}$ produced in cultures with added cyclohexane was corrected for the $\mathrm{H}_{2} \mathrm{~S}$ produced in $\mathrm{C}_{6} \mathrm{H}_{12}$-free bottles

${ }^{d}$ Electrons consumed by $\mathrm{SO}_{4}^{2-}$ reduction divided by electrons from $\mathrm{C}_{6} \mathrm{H}_{12}$ consumed.

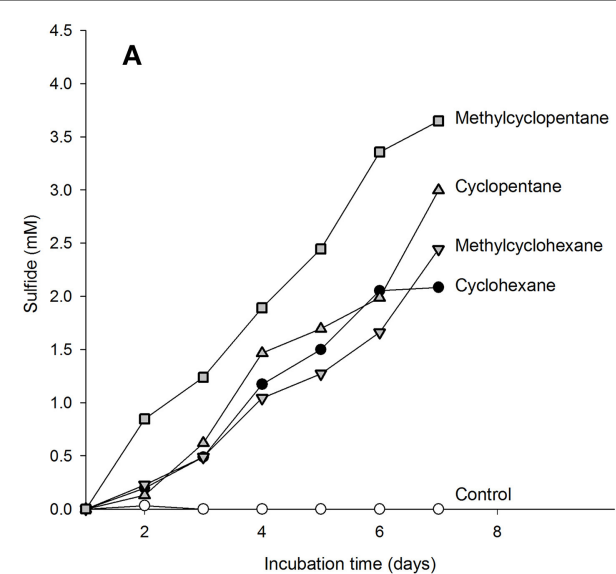

FIGURE 5 | Response of cyclohexane-grown, dense-cell suspensions of the enrichment culture Cyhx28-EdB to additions of cycloalkanes $(A)$, and $n$-alkanes (B), determined as hydrocarbon-dependent sulfate reduction. Cyclohexane-dependent sulfate reduction is shown in both panels as reference $(\bullet)$. The enrichment culture was apparently able to use all cyclic alkanes tested (A), as well as $n$-pentane and $n$-hexane (B). A response to addition of $n$-butane was recorded after a lag phase of 4 days $(\mathbf{B}, \times)$. No

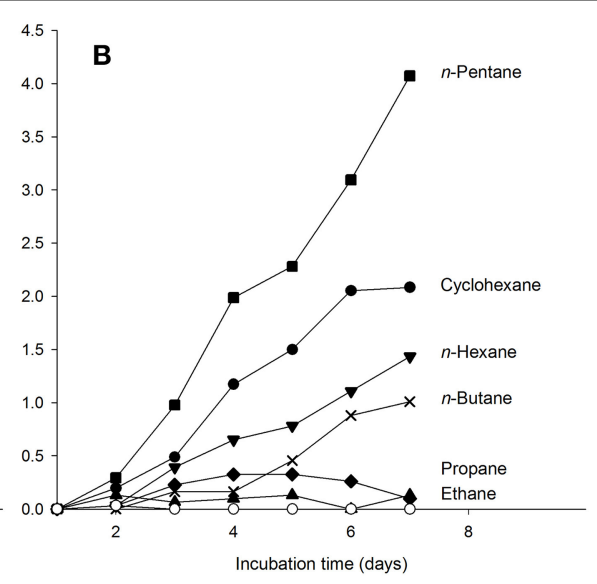

sulfide production could be detected in incubations with ethane, propane (B), and in substrate-free controls $(O$, in both panels). The experiments were performed in anoxic tubes with $10 \mathrm{ml}$ of a $15 \times$ concentrated cell suspension, and confirmed by two independent incubations (here only one data set is shown). CARD-FISH with the sequence-specific probe Cyhx28-EdB_152 showed that the phylotype Cyhx28-EdB-clone63 was dominant in all positive test cultures at the end of the incubation time (Figure SI2). 
and $n$-hexane (Figure 5B). The enrichment culture showed $n$ butane-dependent sulfate-reduction after a lag phase of 4 days (Figure 5B). No sulfate reduction could be detected in incubations with ethane or propane (Figure 5B), or with the aromatic hydrocarbons benzene and toluene (not shown). Hybridizations with the specific probe Cyhx28-EdB_152 showed that the phylotype Cyhx28-EdB-clone63 was highly abundant in all positive substrate test incubations (Figure SI2). These results suggest that the phylotype Cyhx28-EdB-clone63 was most likely responsible for the degradation of the tested hydrocarbons. To date, all reports about microorgansims capable of degrading cycloalkanes under anaerobic conditions showed degradation of single substrates, such as cyclohexane (Musat et al., 2010), ethylcyclopentane (RiosHernandez et al., 2003), or cyclopentene, methylcyclopentene, methylcyclopentane, cyclohexane and methylcyclohexane by distinct sulfate-reducing enrichment cultures (Townsend et al., 2004). In addition, it has been reported that the nitrate reducing strain $\mathrm{HxN1}$ is able to co-activate (but not grow with) cyclopentane and methylcyclopentane during growth on $n$-hexane or crude oil (Wilkes et al., 2003). Given these results and the dominance of the phylotype Cyhx28-EdB-clone63 (>80\%), we hypothesize that Cyhx28-EdB-clone63 is relatively versatile with respect to the range of hydrocarbons utilized, including $\mathrm{C}_{4}-\mathrm{C}_{6} n$ alkanes as well as methyl substituted and unsubstituted five- and six-ring cycloalkanes. Future studies should establish whether other cycloalkane degraders also display a broad substrate range as proposed for the phylotype Cyhx28-EdB-clone63.

The slower sulfate reduction with $n$-hexane vs. cyclohexane may have been caused by the lower solubility in water of the former ( $n$-hexane $0.14 \mathrm{mmol} \mathrm{l}^{-1}$, cyclohexane $0.68 \mathrm{mmol} \mathrm{l}^{-1}$, at $25^{\circ} \mathrm{C}$; data from Eastcott et al., 1988). However, solubility alone cannot explain the observed differences in sulfate reduction with the different substrates. For example, of the hydrocarbons tested cyclopentane has the highest solubility $\left(2.28 \mathrm{mmol}^{-1}\right.$, McAuliffe, 1966; Eastcott et al., 1988), but the sulfate reduction profile with cyclopentane was very similar to that of cyclohexane (Figure 5A). Also, the highest sulfate reduction rate was measured with $n$-pentane, which has a solubility in water similar to that of cyclohexane $\left(0.56 \mathrm{mmol} \mathrm{l}^{-1}\right.$, Eastcott et al., 1988). We rather explain the differences in the sulfate reduction rates as an effect of substrate affinity of the activating enzyme, as shown before in enzyme assays with the (1-methyl)alkylsuccinate synthase from strain HxN1 (Webner, 2012). The more pronounced delayed response to $n$-butane (solubility in water at $25^{\circ} \mathrm{C}, 1.22 \mathrm{mmol} \mathrm{l}^{-1}$ ) may also be due to differences in substrate affinity. However, sulfate reducing bacteria able to utilize $n$-alkanes $\geq \mathrm{C}_{6}$ isolated so far are not able to grow with the short-chain, gaseous alkanes propane and $n$-butane (Widdel et al., 2010). Also, sulfate reducers able to degrade propane and $n$-butane appear to be restricted to these hydrocarbons (Kniemeyer et al., 2007; Jaekel et al., 2013). We may therefore speculate that the delayed response to $n$-butane could have been caused by the induction of different activating enzymes. The presence of two operons encoding for methylalkylsuccinate synthases was so far demonstrated by genome analyses of the alkane-degrading sulfatereducing bacterium D. alkenivorans strain AK-01 (Callaghan et al., 2012). The encoded enzymes may display different affinities

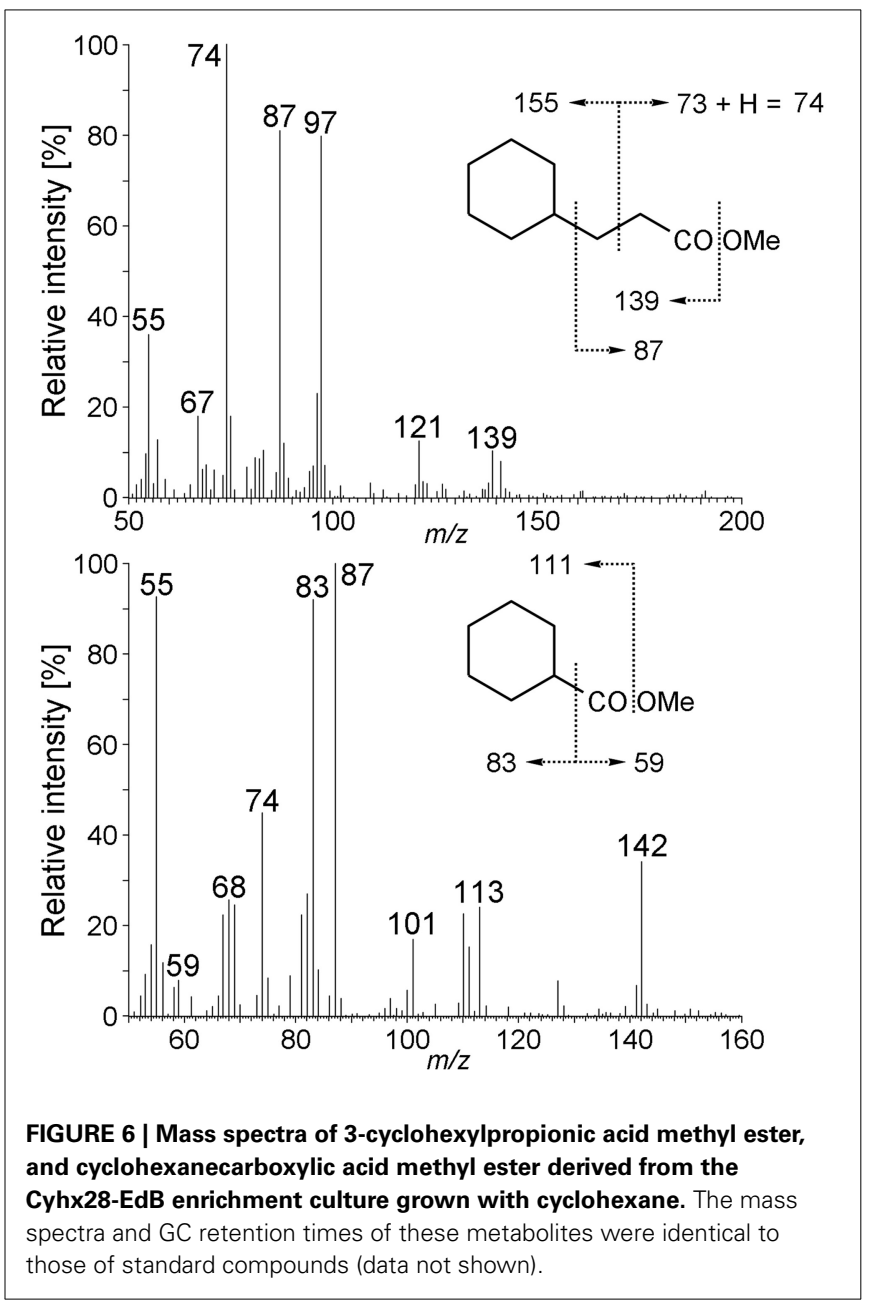

to various hydrocarbon substrates, and may not be constitutively expressed.

\section{ANALYSES OF METABOLITES-EVIDENCE FOR THE ACTIVATION MECHANISM OF CYCLOHEXANE UNDER ANAEROBIC CONDITIONS}

GC-MS analysis of derivatized extracts from cultures grown with cyclohexane in sulfate-limited medium showed the presence of organic acids which were absent in controls without added cyclohexane and in sterile controls. We detected a metabolite whose mass spectrum showed significant fragment ions at $\mathrm{m} / z 114,146,155$, and 197 being in agreement with the structure of cyclohexylsuccinic acid (detected as cyclohexylsuccinic acid dimethyl ester, Figure SI3 and Musat et al., 2010) which was subsequently confirmed by comparison with a standard. The finding of cyclohexylsuccinic acid indicates that the Cyhx28-EdBclone63-dominating culture activates cyclohexane by addition to fumarate. This mechanism of activation is thus similar to the activation of linear saturated hydrocarbons by addition to fumarate at the secondary (subterminal) carbon atom, demonstrated for the first time with $n$-alkane-degrading cultures of nitrate- (Rabus et al., 2001) and sulfate-reducing bacteria (Kropp et al., 2000). Activation by addition to fumarate, which so far appears as the most widespread mode of activation of alkanes (Widdel and 


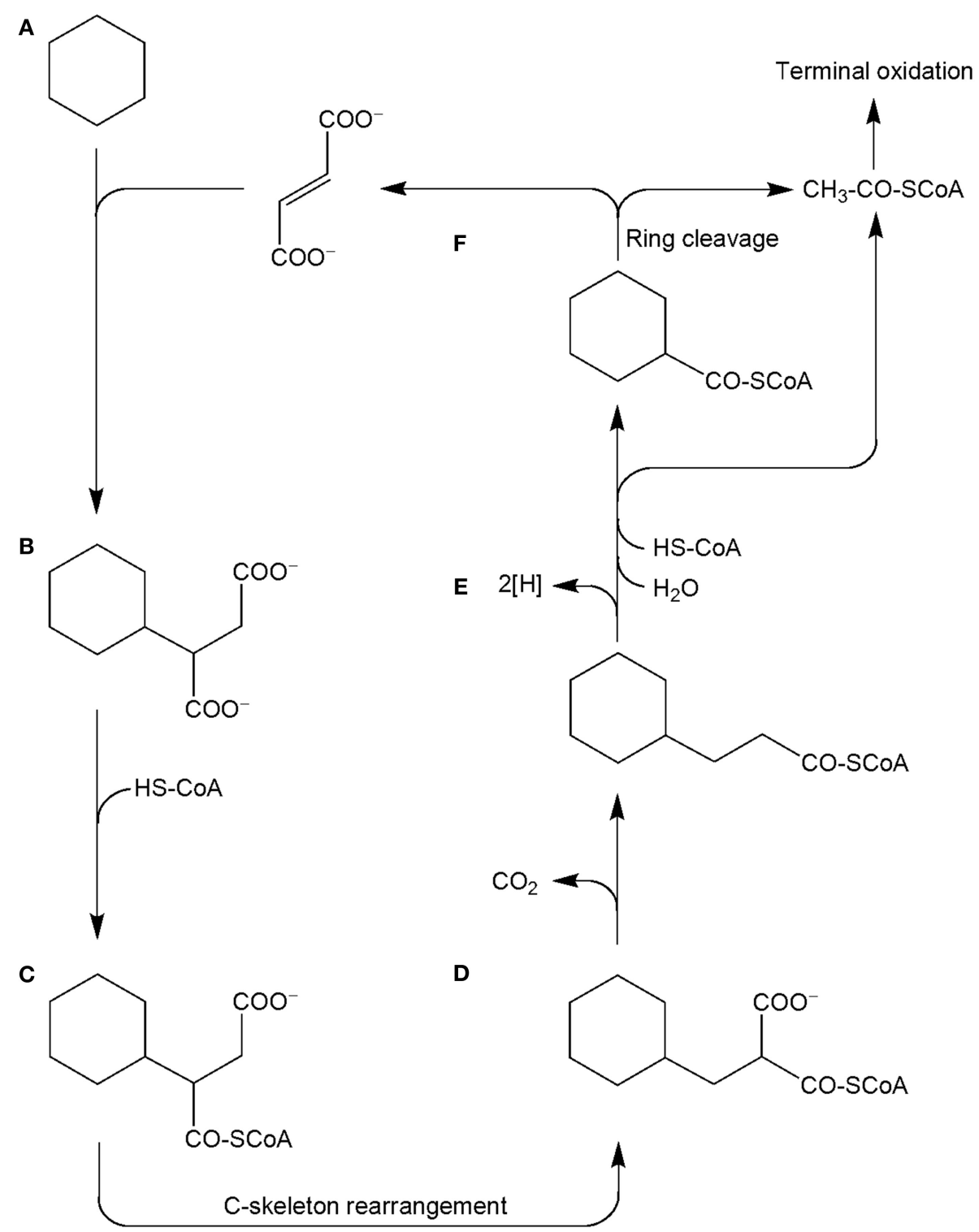

FIGURE 7 | Proposed pathway for the anaerobic degradation of cyclohexane by the enrichment culture Cyhx28-EdB, based on the detected metabolites (marked in bold-face). Cyclohexane (A) is activated by addition to fumarate, to yield cyclohexylsuccinate (B; detected in culture extracts). Cyclohexylsuccinate is further metabolized by activation to cyclohexylsuccinyl-CoA (C), C-skeleton rearrangement to
(cyclohexylmethyl)malonyl-CoA (D) and decarboxylation to 3-cyclohexylpropionyl-CoA (E; detected as metabolite). $\beta$-Oxidation of cyclohexylpropionyl-CoA may explain the formation of cyclohexanecarboxyl-CoA (F). Further oxidation and ring cleavage leads to acetyl-CoA, which is subjected to terminal oxidation and could also be used for the regeneration of fumarate.
Grundmann, 2010), was also demonstrated for the degradation of propane and $n$-butane by strain BuS5, the closest cultured relative of the Cyhx28-EdB-clone63 (Kniemeyer et al., 2007). Activation of cycloalkanes by addition to fumarate was previously reported with a sulfate-reducing enrichment culture degrading ethylcyclopentane (Rios-Hernandez et al., 2003). Cyclohexane activation by the same mechanism was for the first time reported with a nitrate-reducing enrichment culture dominated by Geobacter spp. and Anammox microorganisms (Musat et al., 2010). In addition, methylcyclopentane and cyclopentane, although not serving as growth substrates, were co-activated by addition to fumarate by the nitrate-reducing strain $\mathrm{HxN} 1$ during growth on $n$-hexane or crude oil (Wilkes et al., 2003).

Other metabolites detected in extracts of the culture Cyhx28EdB grown with cyclohexane were identified based on the mass spectra of their corresponding methyl esters and comparison with standards as 3-cyclohexylpropionic acid and cyclohexanecarboxylic acid (Figure 6). The detection of these metabolites provides evidence that cyclohexylsuccinate is further degraded by ligation to coenzyme A, yielding cyclohexylsuccinyl-CoA, carbon-skeleton rearrangement and decarboxylation, yielding 3cyclohexylpropionyl-CoA (detected as 3-cyclohexylpropionate), 
i.e., analogous to the pathway proposed for the degradation of $n$-alkanes (Wilkes et al., 2002) (Figure 7). $\beta$-Oxidation of 3-cyclohexylpropionyl-CoA yields cyclohexanecarboxyl-CoA (detected as cyclohexanecarboxylate) and acetyl-CoA. Further $\beta$-oxidation of cyclohexanecarboxyl-CoA would lead to ring cleavage, yielding pimelyl-CoA, and presumably malonyl-CoA and two acetyl-CoA. Alternatively, pimelyl-CoA could be further degraded via glutaryl-CoA and glutaconyl-CoA, yielding three acetyl-CoA, as proposed for the degradation of pimelate by denitrifying bacteria (Gallus and Schink, 1994). None of these proposed pathways yields fumarate (or succinate), which is essential for the activation of cyclohexane. We speculate that fumarate is synthesized from acetyl-CoA, via carboxylation to pyruvate and oxaloacetate, as previously proposed (Fuchs et al., 1978). Alternatively, fumarate may be regenerated via the propionylCoA pathway, through methylmalonyl-CoA and succinyl-CoA (Textor et al., 1997). Propionyl-CoA, which is most likely not a direct product of the cyclohexane degradation pathway, may be generated by other cellular processes, for example the $\beta$-oxidation of odd fatty acids. The acetyl-CoA could be further degraded to $\mathrm{CO}_{2}$ by the reverse Wood-Ljungdhal pathway, most common in complete-oxidizing sulfate-reducing bacteria (Schauder et al., 1986), as proposed or demonstrated for other alkane-degrading sulfate-reducing bacteria (e.g., Aeckersberg et al., 1991; Callaghan et al., 2012).

\section{CONCLUSIONS}

We report here for the first time the complete degradation of cyclohexane under sulfate-reducing conditions. The enrichment culture obtained from intertidal hydrocarboncontaminated marine sediments was dominated by a single phylotype affiliated with the Desulfosarcina-Desulfococcus cluster of the Deltaproteobacteria. Due to its abundance in the enrichment culture, we propose that this phylotype was responsible for the degradation of cyclohexane. Substrate tests with other hydrocarbons, corroborated with hybridization with sequence-specific oligonucleotide probes suggest that the dominant phylotype has a remarkable substrate range, being able to degrade both cyclic and $n$-alkanes, including the gaseous alkane $n$-butane. This is the first report of a sulfate-reducing bacterium from intertidal marine sediments being able to degrade gaseous alkanes. The current findings further expand our knowledge on the substrate range of Desulfosarcina-Desulfococcus affiliated bacteria, which are often found to be highly abundant in organic matter-rich marine sediments, including intertidal and arctic sediments (Ravenschlag et al., 2000; Llobet-Brossa et al., 2002), and hydrocarbon seep sites (e.g., Orcutt et al., 2010). The abundance of these microorganisms in such environments could be at least in part explained by their ability to degrade hydrocarbons, including cyclic and $n$ alkanes. Degradation of cyclohexane was initiated by addition to fumarate yielding cyclohexylsuccinate, a mechanism of activation commonly employed for the anaerobic degradation of $n$-alkanes. We also identified 3-cyclohexylpropionate, a metabolite which may enter the fatty acid synthesis cycle yielding odd $\omega$-cyclohexyl-substituted fatty acids, as we previously demonstrated with a nitrate-reducing enrichment culture (Musat et al., 2010). Such fatty acids were often found in crude oil samples, with higher concentrations in crude oils affected by a medium to high level of biodegradation (Rodrigues et al., 2005). This suggests that microorganisms as those identified in the present study may be involved in the in situ biodegradation of crude oils under reservoir conditions or in formation waters.

\section{ACKNOWLEDGMENTS}

We thank F. Widdel for supporting the present study and R. Apple for technical assistance. This study was financed by the Max Planck Society, and by the Deutsche Forschungsgemeinschaft (Priority Program SPP1319, grant MU 2950/1-1 to F. Musat).

\section{SUPPLEMENTARY MATERIAL}

The Supplementary Material for this article can be found online at: http://www.frontiersin.org/journal/10.3389/fmicb.2015. 00116/abstract

\section{REFERENCES}

Aeckersberg, F., Bak, F., and Widdel, F. (1991). Anaerobic oxidation of saturated hydrocarbons to $\mathrm{CO}_{2}$ by a new type of sulfate-reducing bacterium. Arch . Microbiol. 156, 5-14. doi: 10.1007/BF00418180

Altschul, S. F., Gish, W., Miller, W., Myers, E. W., and Lipman, D. J. (1990). Basic local alignment search tool. J. Mol. Biol. 215, 403-410. doi: 10.1016/ S0022-2836(05)80360-2

Amann, R. I., Krumholz, L., and Stahl, D. A. (1990). Fluorescent-oligonucleotide probing of whole cells for determinative, phylogenetic, and environmental studies in microbiology. J. Bacteriol. 172, 762-770.

Anderson, M. S., Hall, R. A., and Griffin, M. (1980). Microbial metabolism of alicyclic hydrocarbons: cyclohexane catabolism by a pure strain of Pseudomonas sp. J. Gen. Microbiol. 120, 89-94.

Atlas, R. M., and Hazen, T. C. (2011). Oil biodegradation and bioremediation: a tale of the two worst spills in U.S. history. Environ. Sci. Technol. 45, 6709-6715. doi: 10.1021/es2013227

Brown, R. A., and Huffman, H. L. (1976). Hydrocarbons in open ocean waters. Science 191, 847-849. doi: 10.1126/science.191.4229.847

Bruice, P. Y. (2004). Organic Chemistry. Upper Saddle River, NY: Pearson Education. Callaghan, A. V., Morris, B. E. L., Pereira, I. A. C., McInerney, M. J., Austin, R. N., Groves, J. T. et al. (2012). The genome sequence of Desulfatibacillum alkenivorans AK-01: a blueprint for anaerobic alkane oxidation. Environ. Microbiol. 14, 101-113. doi: 10.1111/j.1462-2920.2011.02516.x

Callaghan, A. V., Wawrik, B. N. Í., Chadhain, S. M., Young, L. Y., and Zylstra, G. J. (2008). Anaerobic alkane-degrading strain AK-01 contains two alkylsuccinate synthase genes. Biochem. Biophys. Res. Commun. 366, 142-148. doi: 10.1016/ j.bbrc.2007.11.094

Cheng, Q., Thomas, S. M., and Rouviere, P. E. (2002). Biological conversion of cyclic alkanes and cyclic alcohols into dicarboxylic acids: biochemical and molecular basis. Appl. Microbiol. Biotechnol. 58, 704-711. doi: 10.1007/s00253002-0958-z

Cord-Ruwisch, R. (1985). A quick method for the determination of dissolved and precipitated sulfides in cultures of sulfate-reducing bacteria. J. Microbiol. Methods 4, 33-36. doi: 10.1016/0167-7012(85)90005-3

Dean, J. A. (1992). Lange's Handbook of Chemistry. New York, NY: McGraw-Hill.

Eastcott, L., Shiu, W. Y., and Mackay, D. (1988). Environmentally relevant physical-chemical properties of hydrocarbons: a review of data and development of simple correlations. Oil Chem. Pollut. 4, 191-216. doi: 10.1016/ S0269-8579(88)80020-0

Fuchs, G., Stupperich, E., and Thauer, R. (1978). Acetate assimilation and the synthesis of alanine, aspartate and glutamate inMethanobacterium thermoautotrophicum. Arch. Microbiol. 117, 61-66. doi: 10.1007/BF00689352

Gallus, C., and Schink, B. (1994). Anaerobic degradation of pimelate by newly isolated denitrifying bacteria. Microbiology 140, 409-416. doi: 10.1099/13500872140-2-409

Glockner, J., Kube, M., Shrestha, P. M., Weber, M., Glockner, F. O., Reinhardt, R., et al. (2010). Phylogenetic diversity and metagenomics of candidate division OP3. Environ. Microbiol. 12, 1218-1229. doi: 10.1111/j.1462-2920.2010.02164.x 
Grundmann, O., Behrends, A., Rabus, R., Amann, J., Halder, T., Heider, J., et al. (2008). Genes encoding the candidate enzyme for anaerobic activation of nalkanes in the denitrifying bacterium, strain HxN1. Environ. Microbiol. 10, 376-385. doi: 10.1111/j.1462-2920.2007.01458.x

Harms, G., Zengler, K., Rabus, R., Aeckersberg, F., Minz, D., Rossello-Mora, R., et al. (1999). Anaerobic oxidation of o-xylene, m-xylene, and homologous alkylbenzenes by new types of sulfate-reducing bacteria. Appl. Environ. Microbiol. 65, 999-1004

Harris, J. K., Caporaso, J. G., Walker, J. J., Spear, J. R., Gold, N. J., Robertson, C. E., et al. (2013). Phylogenetic stratigraphy in the Guerrero Negro hypersaline microbial mat. ISME J. 7, 50-60. doi: 10.1038/ismej.2012.79

Hazen, T. C., Dubinsky, E. A., Desantis, T. Z., Andersen, G. L., Piceno, Y. M., Singh, N., et al. (2010). Deep-sea oil plume enriches indigenous oil-degrading bacteria. Science 330, 204-208. doi: 10.1126/science.1195979

Hugenholtz, P., Tyson, G. W., and Blackall, L. L. (2001). "Design and evaluation of 16S rRNA-targeted oligonucleotide probes for fluorescence in situ hybridization," in Methods in Molecular Biology, ed B. A. Lieberman (Totowa, NJ: Humana Press Inc), 29-41.

Jaekel, U., Musat, N., Adam, B., Kuypers, M., Grundmann, O., and Musat, F. (2013). Anaerobic degradation of propane and butane by sulfate-reducing bacteria enriched from marine hydrocarbon cold seeps. ISME J. 7, 885-895. doi: 10.1038/ismej.2012.159

Jarling, R., Sadeghi, M., Drozdowska, M., Lahme, S., Buckel, W., Rabus, R., et al. (2012). Stereochemical investigations reveal the mechanism of the bacterial activation of n-alkanes without oxygen. Angew. Chem. Int. Ed. Engl. 51, 1334-1338. doi: 10.1002/anie.201106055

Kniemeyer, O., Musat, F., Sievert, S. M., Knittel, K., Wilkes, H., Blumenberg, M., et al. (2007). Anaerobic oxidation of short-chain hydrocarbons by marine sulphate-reducing bacteria. Nature 449, 898-901. doi: 10.1038/nature06200

Kropp, K. G., Davidova, I. A., and Suflita, J. M. (2000). Anaerobic oxidation of $n$-dodecane by an addition reaction in a sulfate-reducing bacterial enrichment culture. Appl. Environ. Microbiol. 66, 5393-5398. doi: 10.1128/AEM.66.12.53935398.2000

Leahy, J. G., and Colwell, R. R. (1990). Microbial degradation of hydrocarbons in the environment. Microbiol. Rev. 54, 305-315.

Llobet-Brossa, E., Rabus, R., Böttcher, M. E., Könneke, M., Finke, N., Schramm, A., et al. (2002). Community structure and activity of sulfate-reducing bacteria in an intertidal surface sediment: a multi-method approach. Aquat. Microb. Ecol. 29, 211-226. doi: 10.3354/ame029211

Ludwig, W., Strunk, O., Westram, R., Richter, L., Meier, H., Yadhukumar, et al. (2004). ARB: a software environment for sequence data. Nucleic Acids Res. 32, 1363-1371. doi: 10.1093/nar/gkh293

Manz, W., Eisenbrecher, M., Neu, T. R., and Szewzyk, U. (1998). Abundance and spatial organization of Gram-negative sulfate-reducing bacteria in activated sludge investigated by in situ probing with specific 16S rRNA targeted oligonucleotides. FEMS Microbiol. Ecol. 25, 43-61. doi: 10.1111/j.15746941.1998.tb00459.x

Mason, O. U., Hazen, T. C., Borglin, S., Chain, P. S., Dubinsky, E. A., Fortney, J. L., et al. (2012). Metagenome, metatranscriptome and single-cell sequencing reveal microbial response to Deepwater Horizon oil spill. ISME J. 6, 1715-1727. doi: 10.1038/ismej.2012.59

McAuliffe, C. (1966). Solubility in water of paraffin, cycloparaffin, olefin, acetylene, cycloolefin, and aromatic hydrocarbons1. J. Phys. Chem. 70, 1267-1275. doi: $10.1021 / \mathrm{j} 100876 \mathrm{a} 049$

Musat, F., and Widdel, F. (2008). Anaerobic degradation of benzene by a marine sulfate-reducing enrichment culture, and cell hybridization of the dominant phylotype. Environ. Microbiol. 10, 10-19. doi: 10.1111/j.14622920.2007.01425.x

Musat, F., Wilkes, H., Behrends, A., Woebken, D., and Widdel, F. (2010). Microbial nitrate-dependent cyclohexane degradation coupled with anaerobic ammonium oxidation. ISME J. 4, 1290-1301. doi: 10.1038/ismej.2010.50

Musat, N., Werner, U., Knittel, K., Kolb, S., Dodenhof, T., Van Beusekom, J. E. E., et al. (2006). Microbial community structure of sandy intertidal sediments in the North Sea, Sylt-Rømø Basin, Wadden Sea. Syst. Appl. Microbiol. 29, 333-348. doi: 10.1016/j.syapm.2005.12.006

Muyzer, G., De Waal, E. C., and Uitterlinden, A. G. (1993). Profiling of complex microbial populations by denaturing gradient gel electrophoresis analysis of polymerase chain reaction-amplified genes coding for $16 \mathrm{~S}$ rRNA. Appl. Environ. Microbiol. 59, 695-700.
Orcutt, B. N., Joye, S. B., Kleindienst, S., Knittel, K., Ramette, A., Reitz, A., et al. (2010). Impact of natural oil and higher hydrocarbons on microbial diversity, distribution and activity in Gulf of Mexico cold seep sediments. Deep Sea Res. II 57, 2008-2021. doi: 10.1016/j.dsr2.2010.05.014

Pachiadaki, M. G., Kallionaki, A., Dahlmann, A., De Lange, G. J., and Kormas, K. A. (2011). Diversity and spatial distribution of prokaryotic communities along a sediment vertical profile of a deep-sea mud volcano. Microb. Ecol. 62, 655-668. doi: 10.1007/s00248-011-9855-2

Pernthaler, A., Pernthaler, J., and Amann, R. (2002). Fluorescence in situ hybridization and catalyzed reporter deposition for the identification of marine bacteria. Appl. Environ. Microbiol. 68, 3094-3101. doi: 10.1128/AEM.68.6.30943101.2002

Perry, J. J. (1984). "Microbial metabolism of cyclic alkanes," in Petroleum Microbiology, ed R. M. Atlas (New York, NY: Macmillan Publishing Co.), 61-99.

Pruesse, E., Quast, C., Knittel, K., Fuchs, B., Ludwig, W., Peplies, J., et al. (2007). SILVA: a comprehensive online resource for quality checked and aligned ribosomal RNA sequence data compatible with ARB. Nucleic Acids Res. 35, 7188-7196. doi: 10.1093/nar/gkm864

Rabus, R., and Widdel, F. (1995). Anaerobic degradation of ethylbenzene and other aromatic hydrocarbons by new denitrifying bacteria. Arch. Microbiol. 163, 96-103. doi: 10.1007/BF00381782

Rabus, R., Wilkes, H., Behrends, A., Armstroff, A., Fischer, T., Pierik, A. J., et al. (2001). Anaerobic initial reaction of $n$-alkanes in a denitrifying bacterium: evidence for (1-methylpentyl)succinate as initial product and for involvement of an organic radical in $n$-hexane metabolism. J. Bacteriol. 183, 1707-1715. doi: 10.1128/JB.183.5.1707-1715.2001

Rabus, R., Wilkes, H., Schramm, A., Harms, G., Behrends, A., Amann, R., et al. (1999). Anaerobic utilization of alkylbenzenes and n-alkanes from crude oil in an enrichment culture of denitrifying bacteria affiliating with the betasubclass of Proteobacteria. Environ. Microbiol. 1, 145-157. doi: 10.1046/j.14622920.1999.00014.x

Ravenschlag, K., Sahm, K., Knoblauch, C., Jorgensen, B. B., and Amann, R. (2000). Community structure, cellular rRNA content, and activity of sulfate-reducing bacteria in marine arctic sediments. Appl. Environ. Microbiol. 66, 3592-3602. doi: 10.1128/AEM.66.8.3592-3602.2000

Redmond, M. C., and Valentine, D. L. (2012). Natural gas and temperature structured a microbial community response to the Deepwater Horizon oil spill. Proc. Natl. Acad. Sci. U.S.A. 109, 20292-20297. doi: 10.1073/pnas.1108756108

Rios-Hernandez, L. A., Gieg, L. M., and Suflita, J. M. (2003). Biodegradation of an alycyclic hydrocarbon by a sulfate-reducing enrichment from a gas condensatecontaminated aquifer. Appl. Environ. Microbiol. 69, 434-443. doi: 10.1128/ AEM.69.1.434-443.2003

Rodrigues, D., de Vasconcellos, S., Alves, P., Nascimento, L., de Abreu, B., de Oliveira, V., et al. (2005). Relationship between cyclohexyl-alkanoic acids and the acidothermophilic bacterium Alicyclobacillus spp.: evidence from Brazilian oils. Org. Geochem. 36, 1443-1453. doi: 10.1016/j.orggeochem.2005. 06.002

Rotaru, A. E., Schauer, R., Probian, C., Mussmann, M., and Harder, J. (2012). Visualization of candidate division OP3 cocci in limonene-degrading methanogenic cultures. J. Microbiol. Biotechnol. 22, 457-461. doi: 10.4014/ jmb. 1110.10055

Rouviere, P. E., and Chen, M. W. (2003). Isolation of Brachymonas petroleovorans CHX, a novel cyclohexane-degrading $\beta$-proteobacterium. FEMS Microbiol. Lett. 227, 101-106. doi: 10.1016/S0378-1097(03)00655-4

Schauder, R., Eikmanns, B., Thauer, R., Widdel, F., and Fuchs, G. (1986). Acetate oxidation to $\mathrm{CO} 2$ in anaerobic bacteria via a novel pathway not involving reactions of the citric acid cycle. Arch. Microbiol. 145, 162-172. doi: 10.1007/ BF00446775

Selesi, D., Jehmlich, N., von Bergen, M., Schmidt, F., Rattei, T., Tischler, P., et al. (2010). Combined genomic and proteomic approaches identify gene clusters involved in anaerobic 2-methylnaphthalene degradation in the sulfate-reducing enrichment culture N47. J. Bacteriol. 192, 295-306. doi: 10.1128/JB.00874-09

Sikkema, J., de Bont, J. A., and Poolman, B. (1994). Interactions of cyclic hydrocarbons with biological membranes. J. Biol. Chem. 269, 8022-8028.

Sikkema, J., de Bont, J. A., and Poolman, B. (1995). Mechanisms of membrane toxicity of hydrocarbons. Microbiol. Rev. 59, 201-222.

Snaidr, J., Amann, R., Huber, I., Ludwig, W., and Schleifer, K. H. (1997). Phylogenetic analysis and in situ identification of bacteria in activated sludge. Appl. Environ. Microbiol. 63, 2884-2896. 
So, C. M., and Young, L. Y. (1999). Isolation and characterization of a sulfate-reducing bacterium that anaerobically degrades alkanes. Appl. Environ. Microbiol. 65, 2969-2976.

Stirling, L. A., Watkinson, R. J., and Higgins, I. J. (1977). Microbial metabolism of alicyclic hydrocarbons: isolation and properties of a cyclohexane-degrading bacterium. J. Gen. Microbiol. 99, 119-125. doi: 10.1099/00221287-99-1-119

Textor, S., Wendisch, V. F., De Graaf, A. A., Müller, U., Linder, M. I., Linder, D., et al. (1997). Propionate oxidation in Escherichia coli: evidence for operation of a methylcitrate cycle in bacteria. Arch. Microbiol. 168, 428-436. doi: 10.1007/ s002030050518

Tissot, B. P., and Welte, D. H. (1984). Petroleum Formation and Occurrence. Berlin: Springer. doi: 10.1007/978-3-642-87813-8

Townsend, G. T., Prince, R. C., and Suflita, J. M. (2004). Anaerobic biodegradation of alicyclic constituents of gasoline and natural gas condensate by bacteria from an anoxic aquifer. FEMS Microbiol. Ecol. 49, 129-135. doi: 10.1016/ j.femsec.2003.08.015

Trower, M. K., Buckland, R. M., Higgins, R., and Griffin, M. (1985). Isolation and characterization of cyclohexane-metabolizing Xanthobacter sp. Appl. Environ. Microbiol. 49, 1282-1289.

Webner, K. (2012). Die Gene der (1-Methylalkyl) succinat-Synthase im Anaeroben $n$-Alkanabbau des Betaproteobakteriums Stamm HxN1. Ph.D., University of Bremen.

Widdel, F., and Bak, F. (1992). "Gram-negative mesophilic sulfate-reducing bacteria," in The Prokaryotes, 2nd Edn., eds A. Balows, H. G. Trüper, M. Dworkin, W. Harder, and K.-H. Schleifer (Berlin; New York: Springer-Verlag), 3352-3378.

Widdel, F., and Grundmann, O. (2010). "Biochemistry of the anaerobic degradation of non-methane alkanes," in Handbook of Hydrocarbon and Lipid Microbiology, ed K. N. Timmis (Berlin: Springer), 909-924. doi: 10.1007/ 978-3-540-77587-4_64

Widdel, F., Knittel, K., and Galushko, A. (2010). "Anaerobic hydrocarbondegrading microorganisms - an overview," in Handbook of Hydrocarbon and Lipid Microbiology, ed K. N. Timmis (Berlin: Springer), 1997-2021.
Wilkes, H., Kuhner, S., Bolm, C., Fischer, T., Classen, A., Widdel, F., et al. (2003). Formation of $n$-alkane- and cycloalkane-derived organic acids during anaerobic growth of a denitrifying bacterium with crude oil. Org. Geochem. 34, 1313-1323. doi: 10.1016/S0146-6380(03)00099-8

Wilkes, H., Rabus, R., Fischer, T., Armstroff, A., Behrends, A., and Widdel, F. (2002). Anaerobic degradation of $n$-hexane in a denitrifying bacterium: further degradation on the initial intermediate (1-methylpentyl)succinate via C-skeleton rearrangement. Arch. Microbiol. 177, 235-243. doi: 10.1007/s00203001-0381-3

Youssef, N., Steidley, B. L., and Elshahed, M. S. (2012). Novel highrank phylogenetic lineages within a sulfur spring (Zodletone Spring, Oklahoma), revealed using a combined pyrosequencing-sanger approach. Appl. Environ. Microbiol. 78, 2677-2688. doi: 10.1128/AEM. 00002-12

Conflict of Interest Statement: The authors declare that the research was conducted in the absence of any commercial or financial relationships that could be construed as a potential conflict of interest.

Received: 11 December 2014; accepted: 29 January 2015; published online: 20 February 2015

Citation: Jaekel U, Zedelius J, Wilkes H and Musat F (2015) Anaerobic degradation of cyclohexane by sulfate-reducing bacteria from hydrocarbon-contaminated marine sediments. Front. Microbiol. 6:116. doi: 10.3389/fmicb.2015.00116

This article was submitted to Microbial Physiology and Metabolism, a section of the journal Frontiers in Microbiology.

Copyright (c) 2015 Jaekel, Zedelius, Wilkes and Musat. This is an open-access article distributed under the terms of the Creative Commons Attribution License (CC BY). The use, distribution or reproduction in other forums is permitted, provided the original author(s) or licensor are credited and that the original publication in this journal is cited, in accordance with accepted academic practice. No use, distribution or reproduction is permitted which does not comply with these terms. 